\title{
ARTE E MUNDO: DIÁLOGOS ENTRE HEIDEGGER E CASTANEDA ${ }^{1}$
}

\author{
Art and World: Dialogues Between Heidegger and Castaneda
}

Arte y Mundo: Diálogos entre Heidegger y Castaneda

Ana Gabriela Rebelo dos Santos

Roberto Novaes De SÁ

\begin{abstract}
Resumo: Propomos pensar possibilidades de experiência de mundo a partir da articulação entre obra de arte, na concepção do filósofo Martin Heidegger em "A Origem da Obra de Arte”, e parar o mundo, idéia exposta pelo antropólogo Carlos Castaneda. Segundo Heidegger, ser obra de arte é instalar um mundo, deixar em aberto o aberto do mundo: abertura de sentido. Para o filósofo, o homem é o ente cujo ser está sempre em jogo na sua existência. "Parar o mundo" é um ensinamento do índio Don Juan a Castaneda. Ele precisa parar o mundo, desmoronar seu conceito de mundo para conseguir ver o mundo desprendido do consenso social. Os autores discorrem sobre realidades plásticas, mundos que existem a partir de experiências, formas de Ec-xistir e transitar entre mundos se mantendo na abertura do ser. Não objetivamos equivaler idéias, buscamos abrir um espaço para pensar acerca da existência do homem. Como recurso metodológico, destacamos passagens da obra de Castaneda e buscamos caminhos junto às idéias de Heidegger que nos auxiliem a elaborar um horizonte de diálogo.
\end{abstract}

Palavras-chave: Fenomenologia; Heidegger; Castaneda; Realidade; Arte.

\begin{abstract}
We propose to consider possibilities of world experience from the relationship between work of art, an idea developed by the philosopher Martin Heidegger in "The Origin of the Work of Art" and stop the world, an idea expounded by the anthropologist Carlos Castaneda. According to Heidegger, being a work of art is to install a world, leave open the opening of the world: opening of sense. For the philosopher, man is the being whose being is always at stake in its existence. "Stop the world," is what speaks the Indian Don Juan to Castaneda. He needs to stop the world, collapsing his concept of world in order to see the world detached from social consensus. The authors discuss plastic realities, worlds that are based on experiences, forms of Existence and sometimes appearing to move between worlds and keeping the opening of Being. We do not aim to equate ideas, we open a space to think about the existence of man. As a methodological resource, we discusses highlighted passages of Castaneda's work and seek ways to the ideas of Heidegger which help us to elaborate a common horizon of dialog.
\end{abstract}

Keywords: Phenomenology; Heidegger; Castaneda; Reality; Art.

Resumen: Nos proponemos estudiar las posibilidades de experiencia de mundo. Partindo de la relación entre obra de arte, una idea desarrollada por el filósofo Martin Heidegger en "El origen de la obra de arte" y detener el mundo, una idea expuesta por el antropólogo Carlos Castaneda. Según Heidegger, ser obra es la instalación de un mundo, mantener abierto el abierto del mundo: el sentido abierto. Para el filósofo, el hombre es el ser cuyo ser está siempre en juego en su existencia. "Detener el mundo," es lo que propone el indio Don Juan a Castaneda. Él tiene que detener el mundo, deshaciendo su concepto del mundo para que pueda ver el mundo separado del consenso social. Los autores hablan de realidades plásticas, de mundos que se basan en las experiéncias, de formas del Existir y permaneciendo en la apertura del ser. La intención no es lo apunte a igualar las ideas, pero abrimos un espacio para pensar en la existencia del hombre. Como método, utilizamos fragmentos de la obra de Castaneda junto de las ideas de Heidegger.

Palabras-clave: Fenomenología; Heidegger; Castaneda; Realidad; Arte.

\section{Introdução}

No verão de 1960, o até então estudante de antropologia Carlos Castaneda parte em viagem para o sudoeste dos Estados Unidos em busca de maiores informações sobre as plantas medicinais utilizadas pelos índios do local. E é no estado do Arizona que acontece o primeiro encontro com o índio yaqui Don Juan Matus. O primeiro de muitos encontros que aconteceriam por mais 13 anos.

\footnotetext{
1 A presente pesquisa foi desenvolvida no Programa de Pós-Graduação em Psicologia da Universidade Federal Fluminense, pela primeira autora (Bolsista Capes), sob orientação do segundo autor.
}

A princípio, Castaneda pede que o índio lhe ensine sobre as plantas, principalmente sobre o peiote, e de alguma forma - que não sabe bem explicar -, se sente intrigado e atraído por Don Juan. Esse primeiro encontro é descrito pelo autor como perturbador.

Depois disso, ainda sob o sentimento de inquietação, Castaneda descobre onde mora Don Juan e passa então a visitá-lo constantemente. Mas, nas longas horas que passavam juntos, durante um ano, não falaram sobre plantas. Os acontecimentos estavam dirigidos para longe de seu propósito original. Passado esse tempo, Don Juan diz a Castaneda ter certos conhecimentos que lhe foram pas- 
sados por seu benfeitor; conhecimentos relacionados ao que ele chama de "caminho do guerreiro". Por uma série de circunstâncias, que não se encerram no desejo de nenhum dos dois, Castaneda fora escolhido como aprendiz de Don Juan e, juntos, trilharam um caminho que abalou definitivamente o mundo daquele.

Os primeiros cinco anos de aprendizado são relatados no seu livro mais famoso - A Erva do Diabo (Castaneda, 1968) -, que foi sua dissertação de mestrado pela Universidade da Califórnia, em Los Angeles. Nele, o autor descreve principalmente suas experiências com plantas alucinógenas, o que foi bastante importante no seu percurso. Cabe aqui lembrar que a visão dos feiticeiros sobre as plantas não se esgota em sua descrição botânica e a experiência de encontro com cada uma delas deve ser vista como um fenômeno, de modo que a coisa com a qual lidamos, nesse caso a planta, nunca é uma coisa ideal e sim a coisa de que fazemos experiência. Dessa forma, é possível manter um olhar de abertura à experiência vivida e ao seu horizonte próprio de sentido.

Os feiticeiros podem se utilizar das plantas como aliados, mas não é necessário que se use. Em passagem de Porta para o infinito (Castaneda, 1974), podemos ver o momento em que Don Juan diz a Castaneda que no caso dele foi preciso fazer uso das plantas, porque ele era um homem muito duro e essas experiências foram necessárias para sacudir seu mundo. Além dessas experiências que incluíam o uso de determinadas plantas, o autor nos fala, ao longo de seus doze livros, de inumeráveis acontecimentos de outros tipos. Aquilo que a princípio lhe parecia mais improvável, foi o que mais lhe atormentou: tudo que ele tomava como o mundo real estava abalado. Diz Castaneda (1972/2006): "O ponto crucial de meu dilema naquele momento era minha falta de vontade de aceitar o fato de que Dom Juan era bem capaz de demolir todas as minhas concepções prévias de mundo...” (p. 39).

Em fins de 1965, Castaneda se retira do aprendizado e decide não mais ver Don Juan. Porém, em 1968, já com seu primeiro livro em mãos, ele vai visitar o índio e a relação mestre-aprendiz é restabelecida. Ao que vem a se passar a partir de então, Castaneda chama de seu segundo ciclo de aprendizado. É nesse segundo ciclo que encontramos aquilo a que vamos dar maior relevância no nosso trabalho: a difícil tarefa de parar o mundo. É preciso que Castaneda consiga "parar o mundo". Mas o que seria "parar o mundo"? Essa pergunta é feita muitas e muitas vezes a seu mestre, que por sua vez, evita palavras e propõe de diversas formas que ele tenha - como Castaneda fala - uma "experiência mais direta do mundo". "Referia-me ao conhecimento acadêmico que transcende a experiência, enquanto ele falava do conhecimento direto do mundo", diz Castaneda (1971/2009, p. 10).

Em outra passagem, quando perguntado sobre o que seria exatamente um ente a que chamam "aliado", em Porta para o Infinito (Castaneda, 1974), Don Juan responde:
- Não há como dizer, precisamente, o que é um aliado, assim como não há meio de dizer exatamente o que é uma árvore.

- Uma árvore é um organismo vivo - disse eu.

- Isso não me diz muito - retrucou ele. Também posso dizer que o aliado é uma força, uma tensão. Mas isso não acrescenta muita coisa a respeito de um aliado. Assim como no caso de uma árvore, o único meio de saber o que é um aliado é experimentando-o (p. 78).

Essas e outras passagens nos fazem recordar os caminhos da fenomenologia, particularmente aqueles trilhados por Martin Heidegger. Propomos que, como o filósofo nos diz em A Questão da Técnica (Heidegger, 1953/1997), atentemos para o caminho sem permanecermos presos a proposições e títulos particulares, e, assim, possamos refletir a partir de uma livre relação de pensamento. Como diz Don Juan, em A Erva do Diabo (Castaneda, 1968), tenhamos em vista que um caminho é apenas um caminho.

Quando Heidegger nos fala de mundo, ele não está falando de um objeto que está ante nós e que pode ser sensorialmente percebido; não se trata de um espaço pré-existente a nós onde as coisas também já ali se encontram dadas e onde somos simplesmente inseridos como bonecos numa caixa. Homem e mundo não pré-existem um ao outro, homem e mundo co-emergem na experiência. Mundo para Heidegger é abertura de sentido. Em A Origem da Obra de Arte, lemos:

Mundo nunca é um objeto, que está ante nós e que pode ser intuído. O mundo é o sempre inobjetal a que estamos submetidos enquanto os caminhos do nascimento e da morte, da benção e da maldição nos mantiverem lançados no Ser (Heidegger, 1950/ 2007, p. 35).

Segundo Heidegger, o sentido está sempre em jogo na existência. Em seu relacionar-se com as coisas enquanto coisas o homem habita o mundo, desvelando sentido. Em nosso modo de ser cotidiano mais comum, tomamos o mundo como algo simplesmente dado, e a nós mesmos como sujeitos empíricos, cuja existência fosse ontologicamente separada do mundo. Quando Castaneda diz conhecer o mundo, ele se refere àquilo que sempre, desde que ele nasceu, as pessoas vem lhe dizendo que é mundo. É importante destacar aquilo que Don Juan nos fala ao longo de toda a obra de Castaneda e que parece ecoar o que a fenomenologia sinaliza como fundamental: a dimensão de abertura da experiência, abertura constitutiva de sentido, porque é na própria relação de sentido que as coisas vêm a ser. Parar o mundo significa desmoronar todo o conceito prévio que se tem de mundo e, assim, o guerreiro vê o mundo desprendido do que se convenciona previamente como mundo. O ver aqui difere do olhar, diz respeito a uma apreensão que não se limita aos olhos, tampouco se determina por um suposto mundo verdadei- 
ro. Quando se "vê", tudo se torna igual e ao mesmo tempo tudo é novo. Tudo se torna igual no sentido do valor, nada é (em si mesmo) mais importante que nada, e ao mesmo tempo tudo é novo por percebermos as coisas desprendidas dos preconceitos cotidianos.

Pensar o mundo como verdadeiro ou falso não faz mais sentido, pois isso implicaria tomarmos como critério um mundo simplesmente dado. Ao longo de seu aprendizado, Castaneda insiste diversas vezes que Don Juan lhe fale o que é ver e o que se vê quando se vê. A isso Don Juan responde:

- Você tem de aprender a ver para saber disso. Não posso lhe dizer.

- É um segredo que não posso saber?

- Não. Acontece que não posso descrevê-lo.

- Por quê?

- Não faria sentido pra você.

- Experimente Don Juan. Talvez faça sentido para $\operatorname{mim}$.

- Não. Tem de fazê-lo por si. Uma vez que aprenda, poderá ver cada coisa no mundo de maneira diferente (Castaneda, 1971/2009, p. 48).

Além deste privilégio dado à experiência como modo de ser irredutível ao conhecimento representacional, é pertinente observarmos, ainda, outra ressonância em nossas leituras de Heidegger e Castaneda referente a essa dimensão existencial do conhecimento: trata-se das noções de fazer e não-fazer, apresentadas por Don Juan a Castaneda. Quando perguntamos, cotidianamente, o que é algo, estamos questionando, na maioria, para que serve a coisa em questão, qual sua função ou utilidade.

Em sua analítica da existência, Heidegger aponta que o nosso modo predominante de ser é o estar absorvido na ocupação com as coisas. Essa "ocupação" não é para ele a mera lida objetiva com coisas previamente dadas, mas uma relação intencional, no sentido fenomenológico, de constituição de sentido. Ocupar-se com as coisas é participar de modo irrefletido da dinâmica de realização de um mundo. Nos deixamos absorver tão firmemente a essa lida ocupacional que deixamos escapar o aberto do mundo. Em uma conferência muito posterior a Ser e Tempo, intitulada A Questão da Técnica, Heidegger (1953/1997) trata mais especificamente do modo moderno e contemporâneo de acontecimento histórico do mundo. Na "era da técnica”, como é denominada, por ele, a época atual, o homem toma todos os entes como recursos para os seus afazeres, como se toda a realidade se reduzisse a mera reserva de energia disponível para sua exploração e consumo (Novaes de Sá \& Rodrigues, 2007). A experiência do pensamento se reduz, por sua vez, às operações calculantes que visam à previsão e ao controle dos entes. Heidegger diz que o mundo atual é pobre de pensamento, querendo significar com isso que a presente era da técnica põe sob ameaça a possibilidade mais essencial do homem: a meditação sobre o sentido das coisas, da existência e do mundo. Para que essa possibilidade seja preservada em meio ao nivelamento calculante promovido pela técnica moderna, Heidegger (1966) propõe o exercício de uma disposição do espírito denominada como serenidade (Gelassenheit). Inspirado no místico alemão Mestre Eckhart, o filósofo entende essa disposição como uma equanimidade da alma, uma atitude de suspensão e desapego da vontade. A "serenidade" faz parte do pensamento que medita. Ao contrário do pensamento calculante, que reduz tudo à condição de disponibilidade, o pensamento meditante nos solicita uma atenção livre de qualquer violência subjetiva, isto é, de qualquer identificação a um aspecto exclusivo das coisas, preservando em sua abertura compreensiva a diferença irredutível entre as realidades que se apresentam e a dinâmica de realização dessas realidades. Em nossas leituras de Castaneda, não pudemos evitar a evocação do "deixar-ser" da "serenidade" heideggeriana quando nos deparamos com a estranha proposta do "não-fazer" de Don Juan.

Antes de parar o mundo, um dos ensinamentos fundamentais que Don Juan apresenta a Castaneda em Viagem a Ixtlan é o "não-fazer". Segundo ele o guerreiro precisa não fazer a fim de experimentar outras possibilidades de ser de uma coisa ao relacionar-se com ela. Destacamos, a seguir, um trecho da referida obra:

- Aquela pedra ali é uma pedra por causa de fazer - disse ele.

...não havia entendido o que ele queria dizer.

- Aquilo é fazer! - exclamou.

- Como?

- Isso também é fazer.

- De que é que está falando, Don Juan?

- Fazer é o que torna aquela pedra uma pedra e um arbusto um arbusto. Fazer é o que torna você, você e eu, eu.

(...)

- Tome aquela pedra por exemplo. Olhar para ela é fazer, mas vê-la é não fazer.

Tive de confessar que as palavras dele não estavam fazendo sentido para mim.

- Ah, fazem, sim! - exclamou. - Mas você está convencido do contrário porque isso é você fazendo. É assim que você age em relação a mim e ao mundo...

- O mundo é o mundo porque você conhece o fazer necessário para torná-lo mundo - disse ele. - Se você não soubesse o seu fazer, o mundo seria diferente (Castaneda, 1972/2006, p. 237).

A fim de não-fazer, Castaneda precisava conseguir parar seu diálogo interno, pois só de olhar uma pedra já estamos fazendo-a pedra pelo nosso pensamento. $\mathrm{O}$ nosso diálogo interno, a todo instante sustenta um mundo que nos é mais familiar. A questão que trazemos é: que mundo temos nós, ao longo dos últimos tempos, feito? Don Juan 
nos fala que todos nós fomos ensinados a concordar sobre o fazer e que não temos idéia de como esse fazer é poderoso, mas felizmente, o não-fazer é igualmente poderoso.

Quando tentamos co-responder à leitura desses pensadores, buscamos abrir um espaço para pensar em novos modos de estar no mundo. Modos que privilegiem as possibilidades de experiência do mundo enquanto mundo. Pensar já é em si uma prática, pois pensamento é uma forma de desvelar mundo. O termo desvelamento (Unverborgenheit), utilizado por Heidegger para traduzir a palavra grega aletheia, indica que a verdade não é a correspondência adequada a uma realidade em si, mas a própria dinâmica de acontecimento/aparecimento das realidades.

A obra de arte, na concepção de Heidegger, tem uma articulação essencial com essas idéias, na medida em que ser obra é instalar um mundo, e para instalar mundo é preciso deixar em aberto o aberto do mundo. A obra coloca à luz o ser das coisas e a possibilidade de abertura e transcendência no relacionar-se com elas. Na referida conferência do filósofo - A Origem da Obra de Arte (Heidegger, 1950/2007) -, ele toma como exemplo algumas telas do pintor holandês Vincent Van Gogh, onde ele pinta sapatos de camponeses. Pares de sapatos camponeses, o que há de especial para se ver aí? Todos nós sabemos de que matéria é feito um sapato, e também conhecemos a serventia do apetrecho sapato.

Na lida cotidiana da camponesa com seus sapatos o que vem ao encontro de modo mais imediato e irrefletido é o caráter instrumental do apetrecho sapato. Seria ilusão pensar que foi a nossa descrição, enquanto atividade subjetiva, que tudo figurou assim para depois projetar no quadro. Essa seria mais uma forma de pensar homem e mundo separados e independentes, com isso acabaríamos fazendo uma gênese psicológica para a criação artística. A seguir, vemos um trecho de Heidegger (1950/2007):

Na escura abertura do interior gasto dos sapatos, fita-nos a dificuldade e o cansaço dos passos do trabalhador. Na gravidade rude e sólida dos sapatos está retida a tenacidade do lento caminhar pelos sulcos que se estendem até longe, sempre iguais, pelo campo, sobre o qual sopra um vento agreste. No couro, está a umidade e a fertilidade do solo. Sob as solas, insinua-se a solidão do caminho do campo, pela noite que cai. No apetrecho para calçar impera o apelo calado da terra, a sua muda oferta do trigo que amadurece e a sua inexplicável recusa na desolada improdutividade do campo no inverno. Por este apetrecho passa o calado temor pela segurança do pão, a silenciosa alegria de vencer uma vez mais a miséria, a angústia do nascimento iminente e o tremor ante a ameaça da morte (p. 25).

Este apetrecho sapato está abrigado no mundo da camponesa e é a partir mesmo desta abrigada pertença que ele surge para o seu repousar-em-si-mesmo. Mas é quando os sapatos estão no quadro que os vemos como possibilidade disso tudo. A obra coloca à luz o ser das coisas e a possibilidade de abertura e transcendência no relacionar-se com elas. É na relação da camponesa com os sapatos que o ser sapato acontece. E esse é o sapato dos longos caminhos pelo campo, do cansaço do trabalho, das horas de frio... É o sapato do qual se tem experiência, são esses sapatos que Vincent abre em suas telas.

Quando Castaneda para o mundo pela primeira vez, ele conversa com um coiote que está andando pelo campo. Ademais, fala de uma série de experiências que diz não poder descrever com palavras. Ao contar o ocorrido ao índio Don Juan, este lhe diz que o coiote não falara da mesma maneira como os homens falam e que Castaneda não conseguiu reconhecer isso, mas seu corpo havia compreendido pela primeira vez.

- Seu corpo compreendeu pela primeira vez. Mas você não conseguiu reconhecer que não era um coiote, para começar, e que certamente não estava falando da maneira que você ou eu falamos.

- Mas o coiote falou mesmo, Don Juan!

- Agora olhe quem está falando como um idiota. Depois de todos esses anos de aprendizado, já devia saber. Ontem você parou o mundo e podia até ter visto. Um ser mágico lhe disse uma coisa e seu corpo foi capaz de entender, porque o mundo tinha desmoronado. - O mundo estava como hoje, Don Juan.

- Não estava, não. Hoje os coiotes não lhe dizem nada, e você não consegue ver as linhas do mundo. Ontem fez tudo isso simplesmente porque alguma coisa tinha parado dentro de você.

- O que foi que parou em mim?

- $\mathrm{O}$ que parou em você ontem foi aquilo que as pessoas têm dito que é o mundo. Entenda, as pessoas nos dizem, desde o momento em que nascemos, que o mundo é assim e assado, naturalmente não temos outra escolha senão ver o mundo do jeito que as pessoas nos dizem que é (Castaneda, 1972/2006, p. 314).

Parar o mundo e ser obra de arte, falando dessas noções, os dois autores discorrem sobre realidades plásticas, sobre mundos que existem a partir de experiências, sobre formas de ec-xistir e transitar entre mundos, mantendo-se na abertura do ente. Quando Van Gogh pinta os sapatos, ele os traz à presença, e aqui entendemos presença como proximidade, a intensidade própria de sua experiência. A arte não consiste em mera representação de um mundo; da mesma forma quando o guerreiro vê, ele faz uma experiência livre de suas idéias prévias de um mundo simplesmente dado. "Parar o mundo", em Castaneda, e "ser obra de arte", em Heidegger, podem ser relecionados pelo fato de apontarem para uma abertura de possibilidades de sentido para além do mundo que tomamos como dado. 
Em Viagem a Ixtlan, após passar por uma determinada experiência, Castaneda se inquieta e diz não conseguir entender o que tinha se passado. Don Juan diz a ele: "Insiste em explicar tudo como se o mundo inteiro fosse composto de coisas que podem ser explicadas. (...) Já lhe ocorreu que há poucas coisas nesse mundo que podem ser explicadas do seu jeito?" (Castaneda, 1972/2006, p. 160).

Quando Castaneda explica o mundo, ele simplesmente reafirma sua representação prévia do mundo e assim o esgota enquanto abertura de possibilidades. Em vários momentos de sua trajetória de aprendizado, Castaneda se vê dividido entre dois mundos, o mundo cotidiano dos homens e o mundo dos feiticeiros: qual mundo seguir?

Certa vez ao ingerir uma das plantas de poder - botões de peiote - ele pergunta qual o caminho certo a seguir, qual o mundo certo. $\mathrm{O}$ espírito do peiote, Mescalito, o conduz em experiências distintas. A princípio, Castaneda tem visões e sensações agradáveis, que lhe trazem felicidade, mas logo depois ruídos começam a entrar nesse mundo pleno de felicidade e a experiência começa a se transformar de forma desagradável. Castaneda se vê em uma situação de luta e todo o conforto desaparece. Diante disso, ele não consegue interpretar sozinho o que foi que Mescalito veio lhe dizer; confuso pede ajuda de Don Juan que lhe diz que a lição de Mescalito foi lindamente clara. Ele disse que Castaneda acredita existirem dois mundos para ele, dois caminhos, enquanto na verdade só existe um: o mundo dos homens.

O único mundo possível para um homem é o mundo dos homens, porque somos homens e isso não podemos resolver largar. Na primeira experiência, onde tudo é felicidade não há diferença entre as coisas porque não há ninguém que indague pela diferença. Por isso Mescalito sacode Castaneda e o tira novamente de uma posição confortável, para lhe mostrar como o homem pensa e luta. Trata-se de um horizonte de mistério fundamental do ser homem: horizonte de abertura da própria existência. Don Juan diz que presumir que se vive em dois mundos é vaidade, pois se sendo homem, se vive o mundo dos homens.

Aproximemos este pensamento com o que desenvolve Heidegger sobre o modo de ser do homem, o "ser-aí". O homem é o único ente cujo ser está sempre em jogo em sua existência. Para a fenomenologia, não há uma essência $a$ priori à própria experiência do existir. $\mathrm{O}$ homem é ser-no-mundo. Don Juan diz que é preciso, de certa forma, entender que, essencialmente, não somos nada para, assim, podermos ser tudo. Nenhum mundo é o mundo certo ou verdadeiro. Mais adiante, em Viagem a Ixtlan, Don Juan fala a Castaneda que após ver o mundo dos feiticeiros ele deverá perceber que a grande arte do guerreiro é saber transitar entre os mundos, sabendo que nenhum é mais verdadeiro que o outro, mas que todos são possibilidades de experiência.
Não devemos concluir desse esboço de um diálogo insólito, que o mundo que convencionamos em sociedade não é importante. O que se põe em questão nesses pensamentos é a cristalização da experiência cotidiana de mundo como verdade absoluta, e, também, a cristalização dos nossos modos de ser medianos como únicas possibilidades de estar no mundo. O nosso modo de ser mais comum é tão próprio ao nosso existir, quanto o fato de que ele não esgota nossas possibilidades existenciais enquanto ser-no-mundo. Mais do que fazer experiências exóticas de mundos, o que buscamos lembrar, através da ressonância entre esses pensamentos tão distintos, seja através da arte ou por outros caminhos, é a "brecha", a "abertura" que nos permite transitar entre mundos.

\section{Referências}

Castaneda, C. (1968). A Erva do Diabo. Rio de Janeiro: Record.

Castaneda, C. (1974). Porta para o infinito. Rio de Janeiro: Record.

Castaneda, C. (2006). Viagem a Ixtlan. Rio de Janeiro: Nova Era (Original publicado em 1972).

Castaneda, C. (2009). Uma estranha realidade. Rio de Janeiro: Nova Era (Original publicado em 1971).

Heidegger, M. (1997). A Questão da técnica. Cadernos de Tradução, número 2. São Paulo: DF/USP (Original publicado em 1953).

Heidegger, M. (2007). A Origem da Obra de Arte. São Paulo: Edições 70 (Original publicado em 1950).

Heidegger, M. (1966) "Sérénité”. Em Questions III, p. 159-181. Paris: Gallimard.

Sá, R. N., de \& Rodrigues, J. T. (2007). A questão do sujeito e do intimismo em uma perspectiva fenomenológico hermenêutica. Em A. M. L. C. de Feijoo \& R. N. de Sá (Orgs). Interpretações fenomenológico-existenciais para o sofrimento psíquico na atualidade [pp. 35-54]. Rio de Janeiro: $\mathrm{GdN} / \mathrm{IFEN}$

Ana Gabriela Rebelo dos Santos - Graduada em Psicologia pela Universidade Federal Fluminense, Mestre em Psicologia pelo Programa de Pós-Graduação em Psicologia da Universidade Federal Fluminense / Bolsista REUNI (UFF) e Arteterapeuta integrante da equipe da Clínica Pomar no Rio de Janeiro. Email: anagabrielarebelo@gmail.com

Roberto Novaes de Sá - Professor Associado da Universidade Federal Fluminense, vinculado ao Programa de Pós-Graduação em Psicologia da UFF. Endereço Institucional: Universidade Federal Fluminense, Centro de Estudos Gerais, Departamento de Psicologia. Campus Gragoatá, bl. O, sala 218 (São Domingos). CEP 24210-350, Niterói (RJ). Email: roberto_novaes@terra.com.br

Recebido em 01.06.2011 Aceito em 21.07.2012 